\title{
Microsegregation in Al-Cu Alloys
}

\author{
E.C. KURUM, H.B. DONG, and J.D. HUNT
}

A comparison has been made between the amount of microsegregation predicted by a numerical model and that found experimentally in $\mathrm{Al}-\mathrm{Cu}$ alloys varying in composition between 1 and 8 wt pct $\mathrm{Cu}$. A depleted region was predicted and observed experimentally near the $\mathrm{Al}_{2} \mathrm{Cu}$. The depleted region was formed below the eutectic temperature and had a significant effect on the ordered compositionfraction plots, particularly for high alloy compositions. Although the fit between experiment and theory was reasonably good, it was concluded that it was necessary to propose that local equilibrium was not maintained between the phases in the solid-state reactions.

\section{INTRODUCTION}

EARLIER work on microsegregation was carried out by the authors in $\mathrm{Al}-\mathrm{Cu}$ alloys using heat evolution in a sensitive single-pan calorimeter. ${ }^{[1,2]}$ It was pointed out, in the articles, that it is not possible to measure directly the fraction solid as a function of temperature and, thus, the amount of microsegregation using calorimetry, unless it is assumed that the latent heat is constant and the heat evolved does not depend on the composition changes that occur during solidification. However, it was possible to compare the heat evolved using a model of microsegregation and a thermophysical software program like MTDATA ${ }^{[3]}$ When this comparison was made, the experimental results compared well with the predictions, except at the highest $\mathrm{Cu}$ concentrations ${ }^{[1]}$ Despite the reasonable agreement, it was recognized that calorimetry was a relatively insensitive method for investigating the progress of microsegregation, because there was only a small change in the amount of heat evolved for the two extremes of equilibrium freezing and there was no diffusion in the solid. For this reason, additional experiments were carried out, investigating the amount of microsegregation using the more traditional method of measuring composition as a function of sample fraction. ${ }^{[4]}$ It was concluded that, although the amount of eutectic at the eutectic temperature measured using the calorimeter was as predicted, the final ordered compositionfraction plot did not fit well, particularly at high $\mathrm{Cu}$ concentrations. This type of behavior has been found by other authors. ${ }^{[5,6]}$ It was noticed that small changes in the phase diagram (in particular, the solidus and solvus) and the temperature dependence of the solid-diffusion coefficient affected the predicted results. For this reason, parts of the phase diagram and the solid-state diffusion coefficient were remeasured as a check on the input data. The results of these measurements and a comparison with a new series of $\mathrm{Al}-\mathrm{Cu}$ alloys, varying from 1 to $8 \mathrm{wt}$ pct $\mathrm{Cu}$, are reported in this article.

E.C. KURUM recently completed her Ph.D. in Department of Materials, University of Oxford. Contact e-mail: ebru.kurum@gmail.com H.B. DONG, Lecturer, is with the Department of Engineering, University of Leicester, Leicester, LE1 7RH, United Kingdom. J.D. HUNT, Emeritus Professor, is with the Department of Materials, University of Oxford, Oxford, OX1 3PH, United Kingdom.

Manuscript submitted October 29, 2004.

\section{EXPERIMENTAL PROCEDURE}

\section{A. Measurement of the Phase Diagram}

Superpure Al (99.9999 wt pct) and pure Cu (99.999 wt pct) were used to make up the alloys. The measured alloy compositions are shown in Table I.

The liquidus was measured using the single-pan calorimeter. The thermocouples were calibrated with pure $\mathrm{Al}$, and the liquidus temperature was taken to be the break as the last solid melts. The results are shown in Table II and Figure 1. The results do not differ significantly from previous work.

The solidus and solvus were measured using electronprobe microanalysis (EPMA) after a long anneal at a number of different temperatures. ${ }^{[14]}$ The length of the anneal was made greater than $10 x^{2} / D$ (where $x$ is the scale of the microstructure and $D$ is the solid-state diffusion coefficient). The results are shown in Tables III and IV. Figure 2 compares the results with previous work. The solidus line is toward the top of the previous results and is well away from that predicted by MTDATA. The solvus line agrees reasonably well with that predicted by MTDATA, but is above that of Matsuyama. ${ }^{[10]}$ The phase diagram used in the future calculations is shown by the dotted line in Figure 2.

\section{B. Measurement of the Solid-State Diffusion Coefficient}

The solid-state diffusion coefficient was measured using an $\mathrm{Al} / / \mathrm{Al}-2$ wt pct $\mathrm{Cu}$ diffusion couple, prepared by Alcan International Research Laboratories using roll bonding. ${ }^{[14]}$ The composition-distance plots before and after annealing were measured using EPMA along a series of lines $(15 \mu \mathrm{m}$ apart) parallel to the junction between the two materials. The composition along the line was averaged and plotted against distance. Three different annealing temperatures were used. The composition profile was fitted with the least-squares error fit for all the points, assuming a constant diffusion coefficient. ${ }^{[14]}$ From this Arrhenius plot, the pre-exponential constant $\left(D_{o}\right)$ is taken to be $2.0410^{-5} \mathrm{~m}^{2} / \mathrm{s}$ and the activation energy is taken to be $127.504 \mathrm{~kJ} / \mathrm{mol}$. The results, using $D_{o}$ and the activation energy, are compared with previous work in Figure 3.

\section{Measurement of the Composition-Fraction Plots}

The technique used to more directly measure the microsegregation in this work and in the authors' earlier work was Gungor's method. ${ }^{[4]}$ Using this technique, the composition 
Table I. Actual Compositions (Wt Pet Cu) of the Al-Cu Samples

\begin{tabular}{lcccccccc}
\hline Sample Name & 1 pct $\mathrm{Cu}$ & 2 pct $\mathrm{Cu}$ & 3 pct $\mathrm{Cu}$ & 4 pct $\mathrm{Cu}$ & 5 pct $\mathrm{Cu}$ & 6 pct $\mathrm{Cu}$ & 7 pct $\mathrm{Cu}$ & 8 pct $\mathrm{Cu}$ \\
\hline Measured composition (wt pet $\mathrm{Cu})$ & 0.98 & 1.97 & 2.96 & 3.97 & 4.85 & 5.86 & 6.93 & 7.91 \\
\hline
\end{tabular}

Table II. The Measured Liquidus Temperatures

\begin{tabular}{lrrrrrrr}
\hline $\begin{array}{c}\text { Composition } \\
(\text { wt pct Cu) }\end{array}$ & 1.97 & 3.97 & 4.85 & 5.86 & 6.93 & 7.91 & 32.5 \\
$\begin{array}{c}\text { Temperature } \\
\left( \pm 1^{\circ} \mathrm{C}\right)\end{array}$ & 655.9 & 649.7 & 646.8 & 644.2 & 640.99 & 638.5 & 549.5 \\
\hline
\end{tabular}

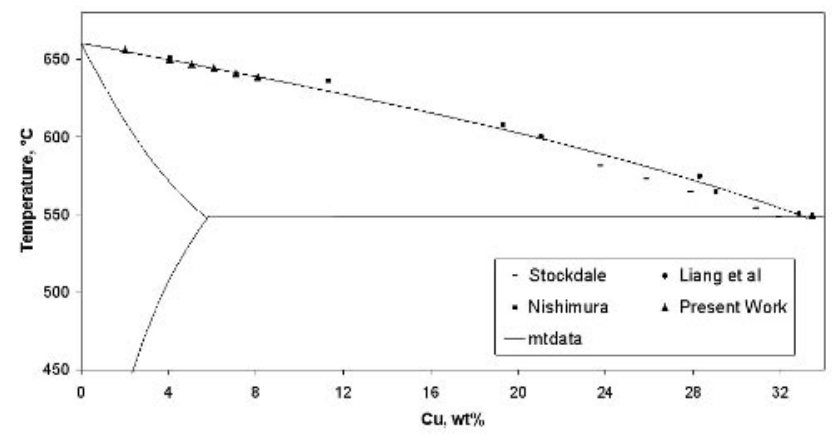

Fig. 1-Measured Al-Cu liquidus curve compared with previous data (those of Stockdale, ${ }^{[7]}$ Nishimura, ${ }^{[8]}$ and Liang ${ }^{[9]}$ ).

Table III. Solidus Measurements

\begin{tabular}{lcccc}
\hline $\begin{array}{l}\text { Annealing } \\
\text { Temperature } \\
\left( \pm 1{ }^{\circ} \mathrm{C}\right)\end{array}$ & 626 & 597.6 & 574.6 & 553 \\
$\begin{array}{l}\text { Composition } \\
\text { in the } \mathrm{Al} \\
(\text { wt pct } \mathrm{Cu})\end{array}$ & $2.02 \pm 0.03$ & $3.50 \pm 0.05$ & $4.81 \pm 0.07$ & $6.12 \pm 0.09$ \\
\hline
\end{tabular}

Table IV. Solvus Measurements

\begin{tabular}{lcccc}
\hline $\begin{array}{l}\text { Annealing } \\
\text { Temperature } \\
\left( \pm 1{ }^{\circ} \mathrm{C}\right)\end{array}$ & 547 & 523 & 500 & 475 \\
$\begin{array}{l}\text { Composition } \\
\text { in the } \mathrm{Al} \\
(\text { wt pct } \mathrm{Cu})\end{array}$ & $6.01 \pm 0.09$ & $4.93 \pm 0.07$ & $4.35 \pm 0.06$ & $3.29 \pm 0.05$ \\
\hline
\end{tabular}

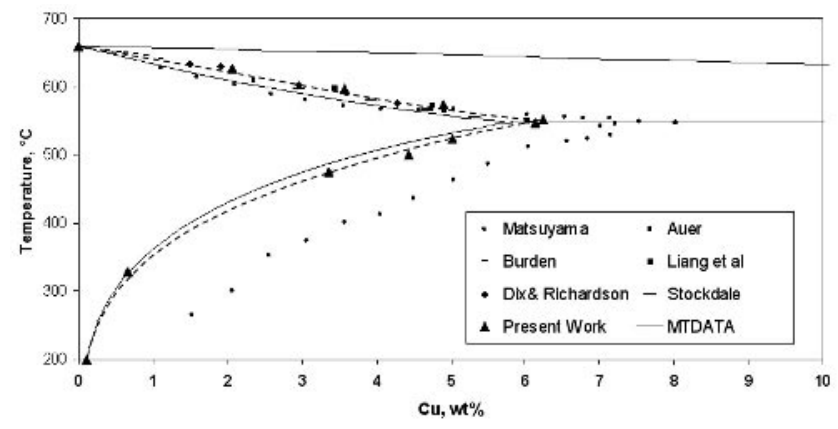

Fig. 2-Solidus and solvus data presented on an Al-Cu phase diagram plotted with a previously measured $\mathrm{Al}$ corner of the $\mathrm{Al}-\mathrm{Cu}$ phase diagram (data provided by Matsuyama, ${ }^{[10]}$ Burden,,${ }^{[1]}$ Dix and Richardson, ${ }^{[12]}$ and Auer $\left.{ }^{[13]}\right)$.

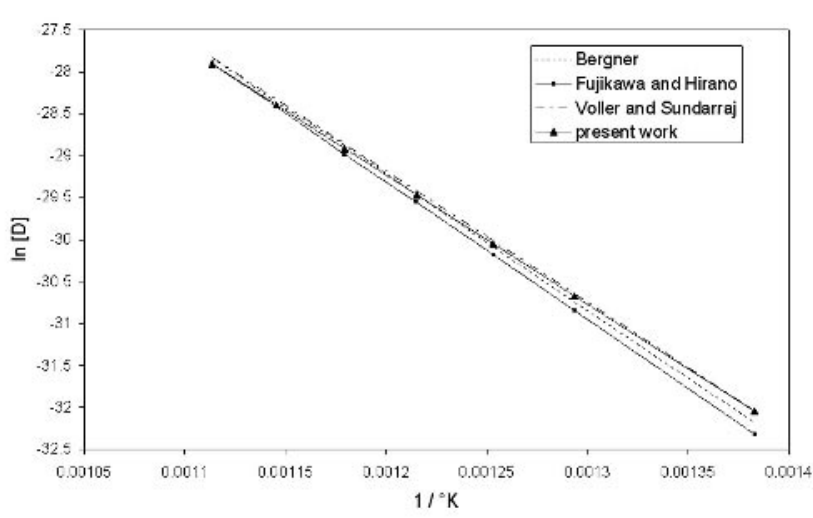

Fig. 3-Comparison of the measured diffusion coefficient with previous data (that of Bergner, ${ }^{[15]}$ Fujikawa and Hirano, ${ }^{[16]}$ and Voller and Sundarraj ${ }^{[17]}$ ).

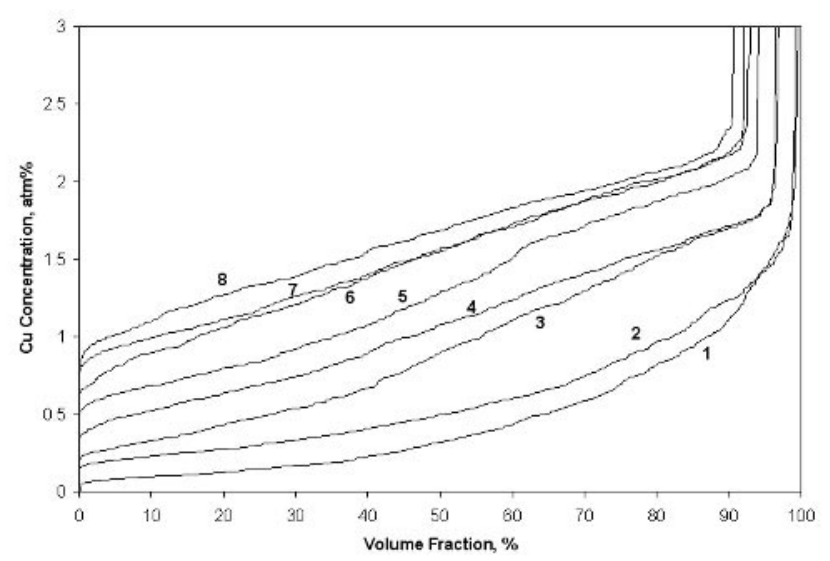

Fig. 4-The ordered microsegregation data plotted as volume fraction $v s$ $\mathrm{Cu}$ concentration, for the 1 to $8 \mathrm{pct} \mathrm{Cu}$ alloys listed in Table I.

is measured at the corners of a random grid. The compositions are then sorted and plotted in ascending order of concentration against the fraction of the points. The fraction of the points becomes the sample-fraction axis.

The composition of the alloys is shown in Table I. The alloys were heated in a single-pan calorimeter to the melting temperature and then cooled with a cooling rate of about $0.05{ }^{\circ} \mathrm{C} / \mathrm{s}$, before latent heat was evolved. The samples were polished to a $1 \mu \mathrm{m}$ finish and analyzed in a JEOL* JXA

*JEOL is a trademark of Japan Electron Optics Ltd., Tokyo.

8800 microprobe: a square grid was placed on the samples, and 676 points at grid corners were analyzed per sample. The side of the grid was made much larger than the dendrite spacing and was not less than $1 \mathrm{~mm}$. The points were then ordered as described earlier and are shown in Figure 4. Backscattered images of the samples were taken and are shown in Figure 5. 


\section{COMPARISON OF THE MODEL PREDICTIONS WITH EXPERIMENT}

The plots in Figure 4 were compared with predictions calculated using the numerical model named Alloy. ${ }^{[18]}$ Alloy is a fully implicit backdiffusion-based model treating diffusion in a cylinder. More details of the model are given in Reference 19. The actual temperature-time curves, obtained in the calorimeter for the different alloys, were used as an input to the model. The solid-state diffusion coefficient is assumed to vary with temperature, and an allowance is made for the dendrite-tip undercooling. Local equilibrium is assumed to occur at the boundary between phases. Thus, after the eutectic temperature, the aluminum at the boundary between the single phase and the eutectic should follow the solvus. This leads to one of the complications of using Gungor's method to measure microsegregation. Since the solid solubility of $\mathrm{Cu}$ in $\mathrm{Al}$ is reduced below the eutectic temperature, the boundary composition in the primary $\mathrm{Al}$ is reduced to a level often lower than that at the center of the dendrite. A true microsegregation plot is then similar to the experimentally measured plot along the line shown in Figure 6 for the 4 pct $\mathrm{Cu}$ alloy. The important point is that the

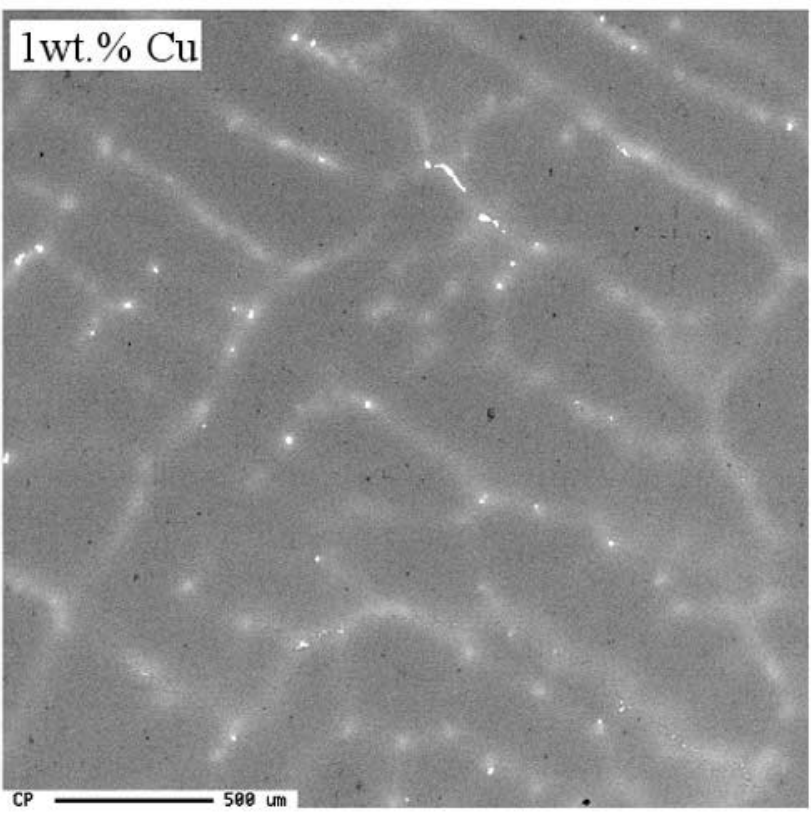

(a)

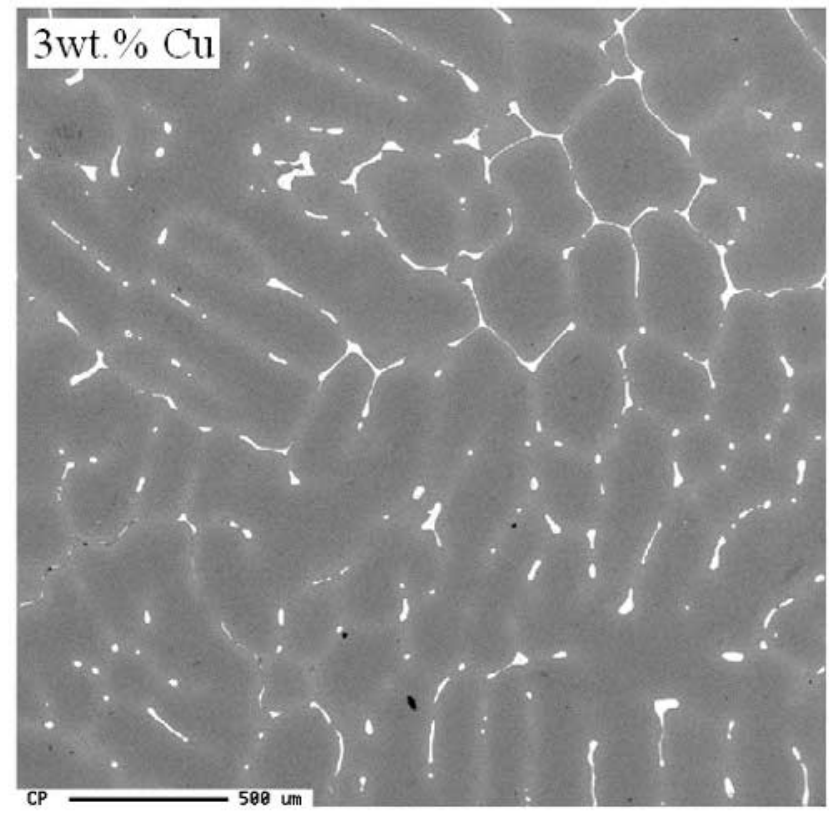

(c)

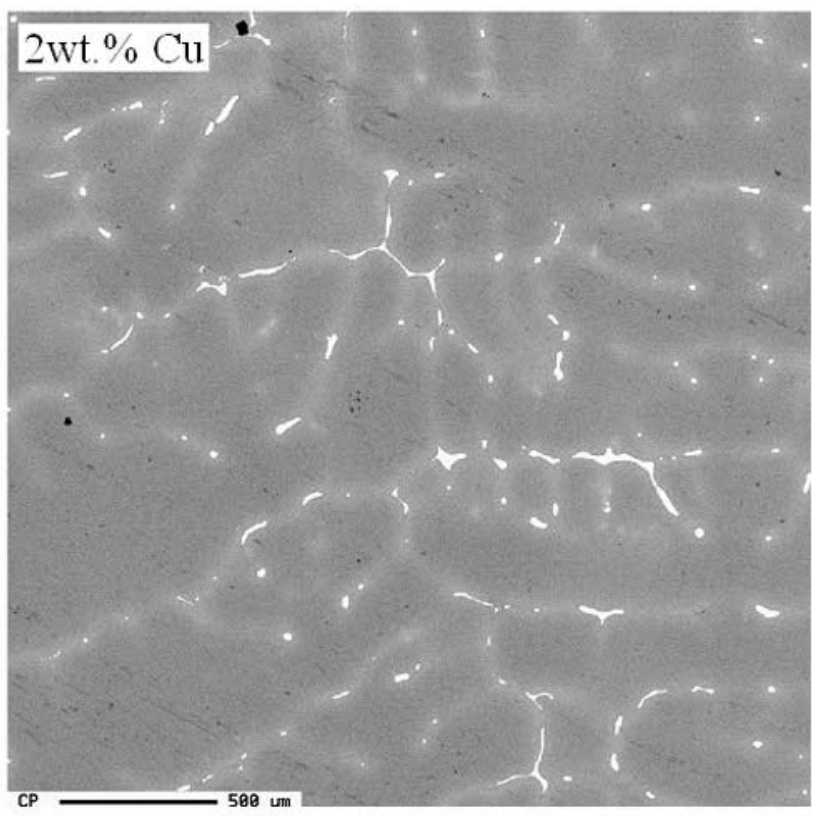

(b)

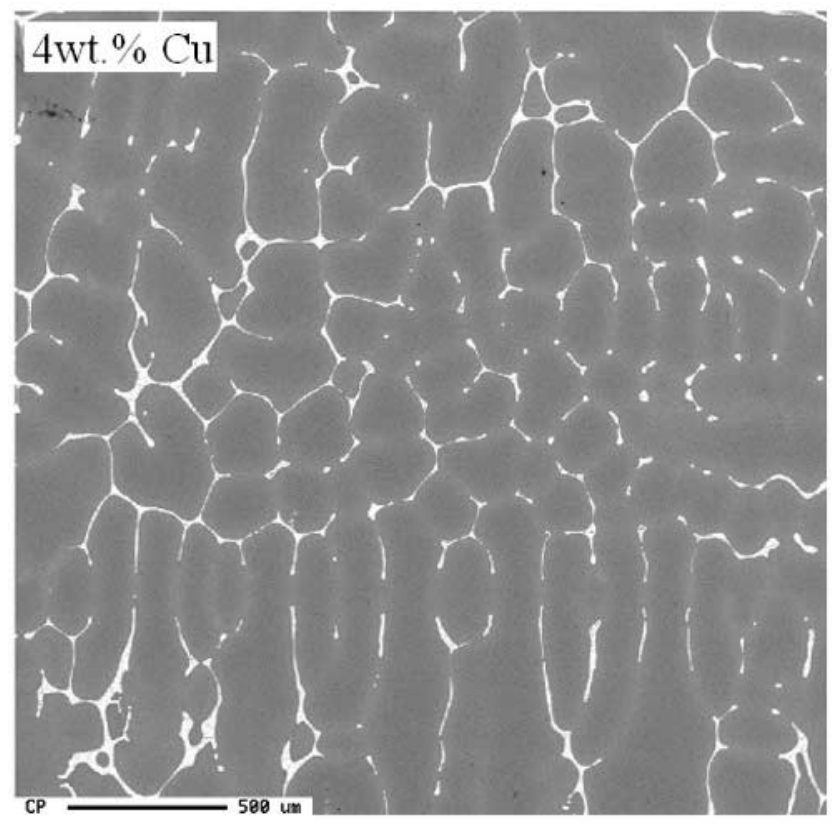

(d)

Fig. 5-Backscattered images of the 1 to 8 pct Cu samples taken in the microprobe. Scale bar is $500 \mu \mathrm{m}$ in all images (acquired at 40 times magnification). 


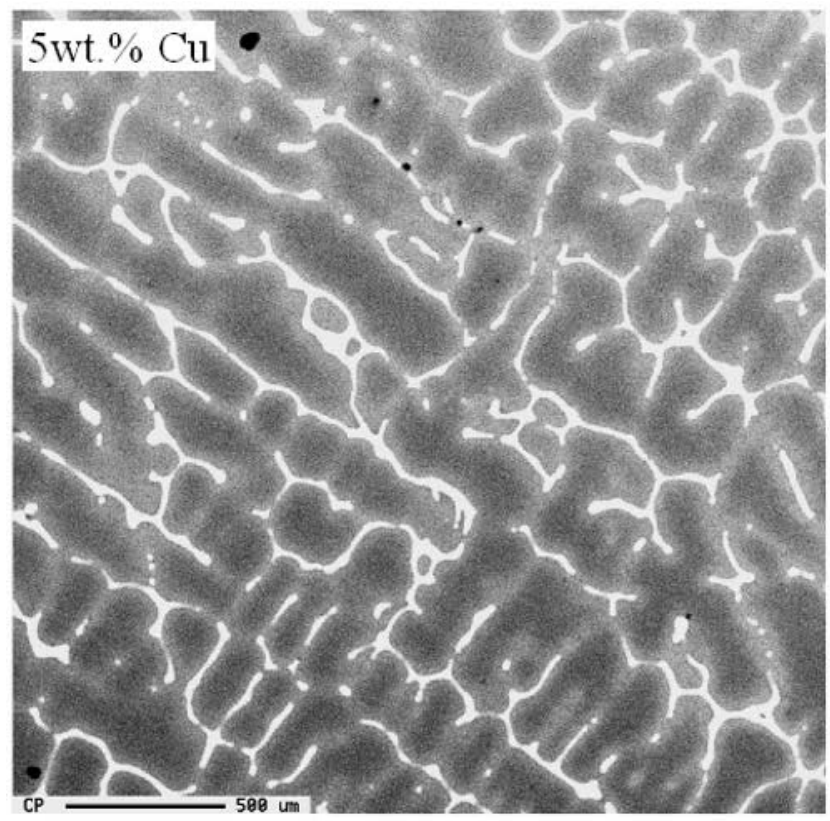

(e)

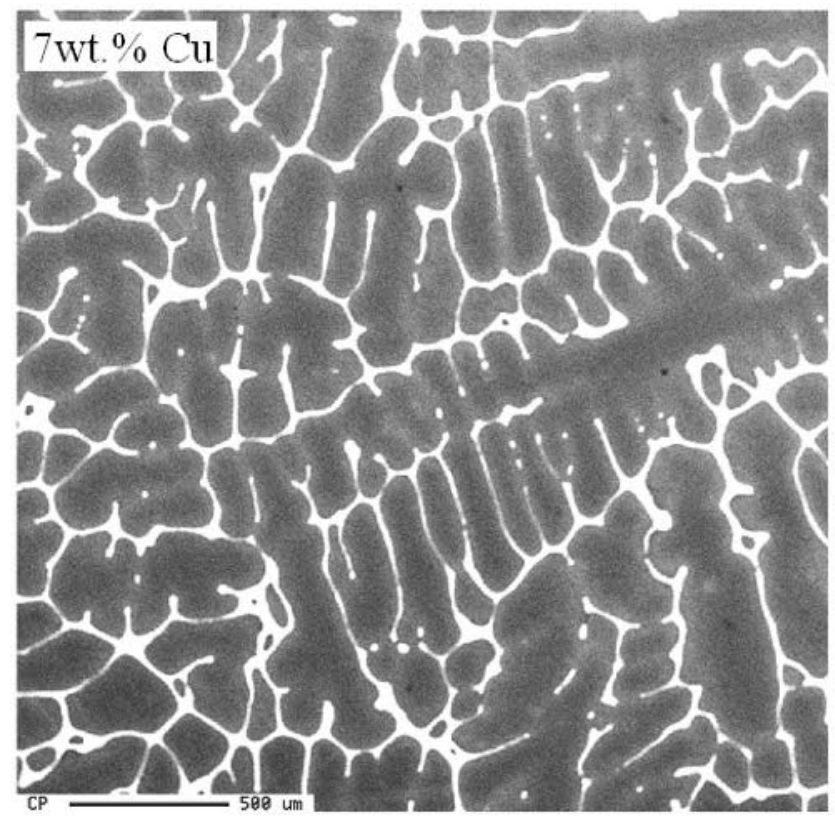

(g)

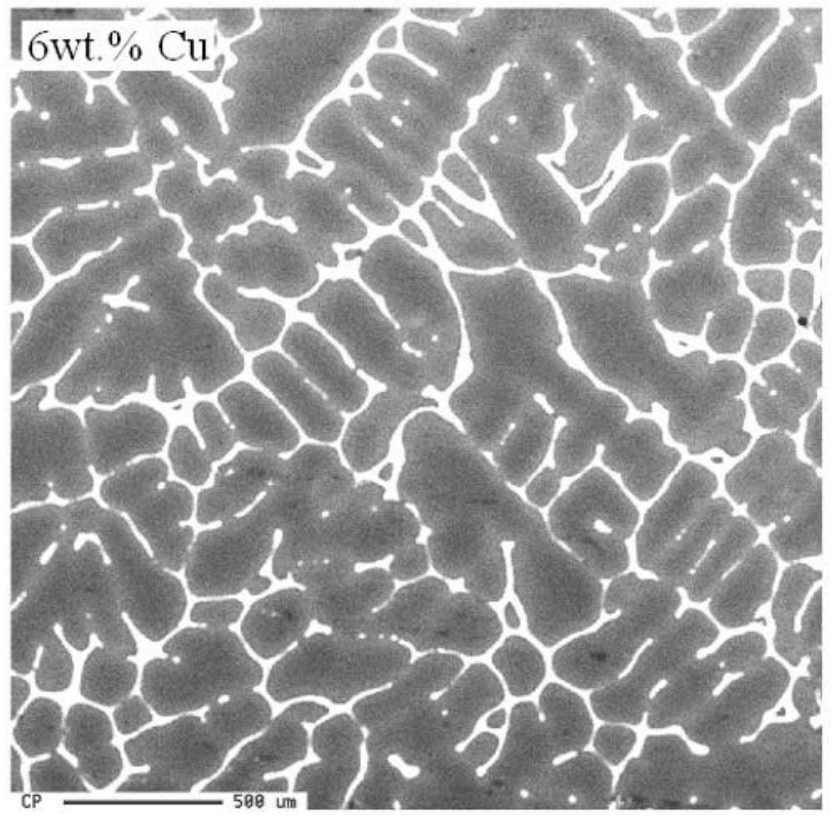

(f)

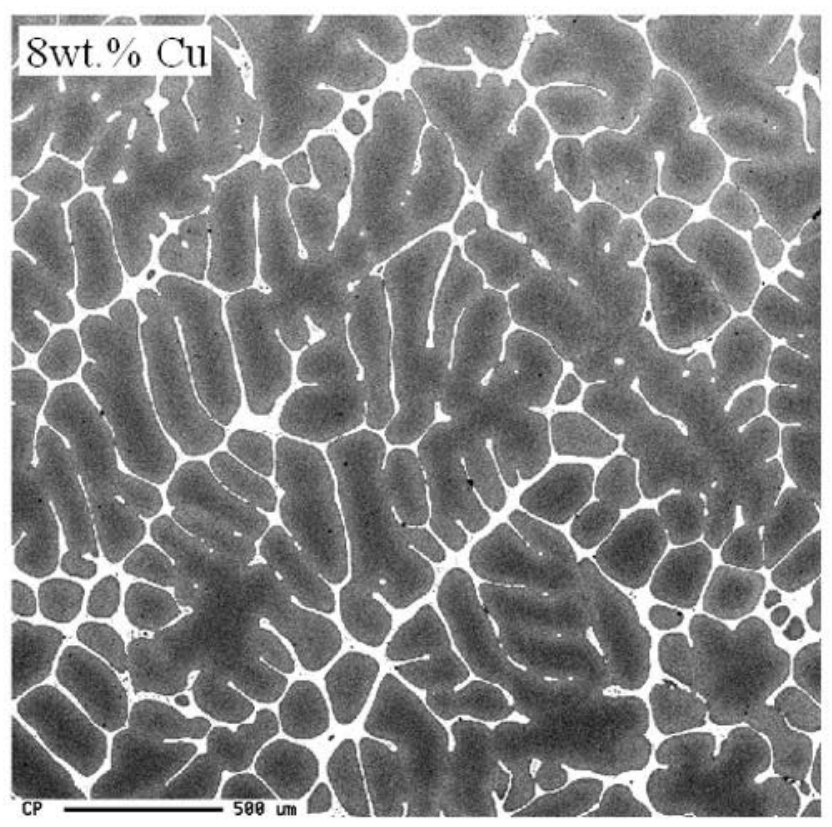

(h)

Fig. 5-(Continued). Backscattered images of the 1 to 8 pct $\mathrm{Cu}$ samples taken in the microprobe. Scale bar is $500 \mu \mathrm{m}$ in all images (acquired at 40 times magnification).

peak concentration occurs some distance away from the boundary. This observation illustrates the fact that the Gungor plot is not a microsegregation plot when more than one phase is present. This observation seems to have been neglected in the past. For comparison with experimental measurements, the predicted microsegregation plot obtained from the numerical model was converted into ordered plots (this was done by taking the composition of each control volume and placing them in ascending order while summing the relevant volumes).

The newly measured phase diagram and the diffusion coefficient were used for the calculations. The program was run while treating the spacing as a variable to see whether any one spacing would fit the experimental plots, since it would be impossible to get a definitive single spacing from the microstructure. The approximate spacings are given in Table V. The simulations with three different spacings are shown in Figures 7(a) through (h). The three spacings were chosen arbitrarily, but were chosen to be similar to those crudely estimated from the samples (Table V).

For the 1 pct $\mathrm{Cu}$ alloy shown in Figure 7(a), a good fit is obtained at low compositions for a spacing of $330 \mu \mathrm{m}$. However, changing the spacing to get a better fit at high 
concentrations caused the fit to be lost at low concentrations. The model did not predict any eutectic for the three spacings shown, but a very small amount was found in the compositional measurements.

For the 2 pct $\mathrm{Cu}$ alloy, there is a reasonable fit at low concentrations for the spacing of $260 \mu \mathrm{m}$ (Figure 7(b)) but, again,

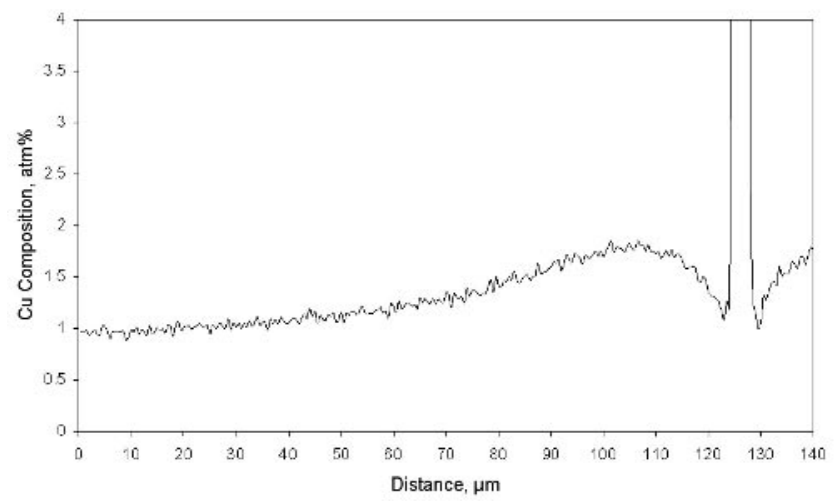

Fig. 6-Compositional line scan taken between the center of the dendrite and the eutectic (measured in the 4 pct $\mathrm{Cu}$ alloy). the overall fit is not improved by changing the spacing. No eutectic was predicted for the two smaller spacings, but it was present for the largest spacing. It is interesting to note the change in the form of the profile when eutectic forms. This is the result of the $\mathrm{Al}$ in the boundary following the solvus.

For the 3 and 4 pct $\mathrm{Cu}$ samples, a good fit can be obtained over much of the sample (Figures 7(c) and (d)), but there is a poor fit at the highest concentrations. Eutectic is predicted for all three spacings.

Similar results were obtained for the $5,6,7$, and 8 pct $\mathrm{Cu}$ alloys, but the overall fit gets worse as the composition increases from 5 to 8 pct $\mathrm{Cu}$ (Figures 7(e) through (h)).

Various reasons can be suggested to explain the poor fit at high concentrations or high volume fractions.

(1) The volume activated by the electron beam in the microprobe is about $2 \mu \mathrm{m}$ and could contain two phases (Al and $\mathrm{Al}_{2} \mathrm{Cu}$ ), giving higher $\mathrm{Cu}$ contents than actually exist. This explanation is useful to explain the poor fit near the boundary, but it is not sufficient to explain the more extensive poor fit in the samples.

(2) Any real structure consists of a wide range of spacings. In principle, it is possible that a combination of different spacings could lead to a fit over the whole composition range. This explanation is unlikely because, at the

Table V. The Approximate Size of the Microstructures

\begin{tabular}{llllllll}
\hline 1 pct $\mathrm{Cu}$ & 2 pct $\mathrm{Cu}$ & 3 pct Cu & 4 pct Cu & 5 pct Cu & 6 pct $\mathrm{Cu}$ & 7 pct $\mathrm{Cu}$ & $8 \mathrm{pct} \mathrm{Cu}$ \\
\hline $390 \mu \mathrm{m}$ & $330 \mu \mathrm{m}$ & $250 \mu \mathrm{m}$ & $200 \mu \mathrm{m}$ & $185 \mu \mathrm{m}$ & $175 \mu \mathrm{m}$ & $150 \mu \mathrm{m}$ & $130 \mu \mathrm{m}$ \\
\hline
\end{tabular}
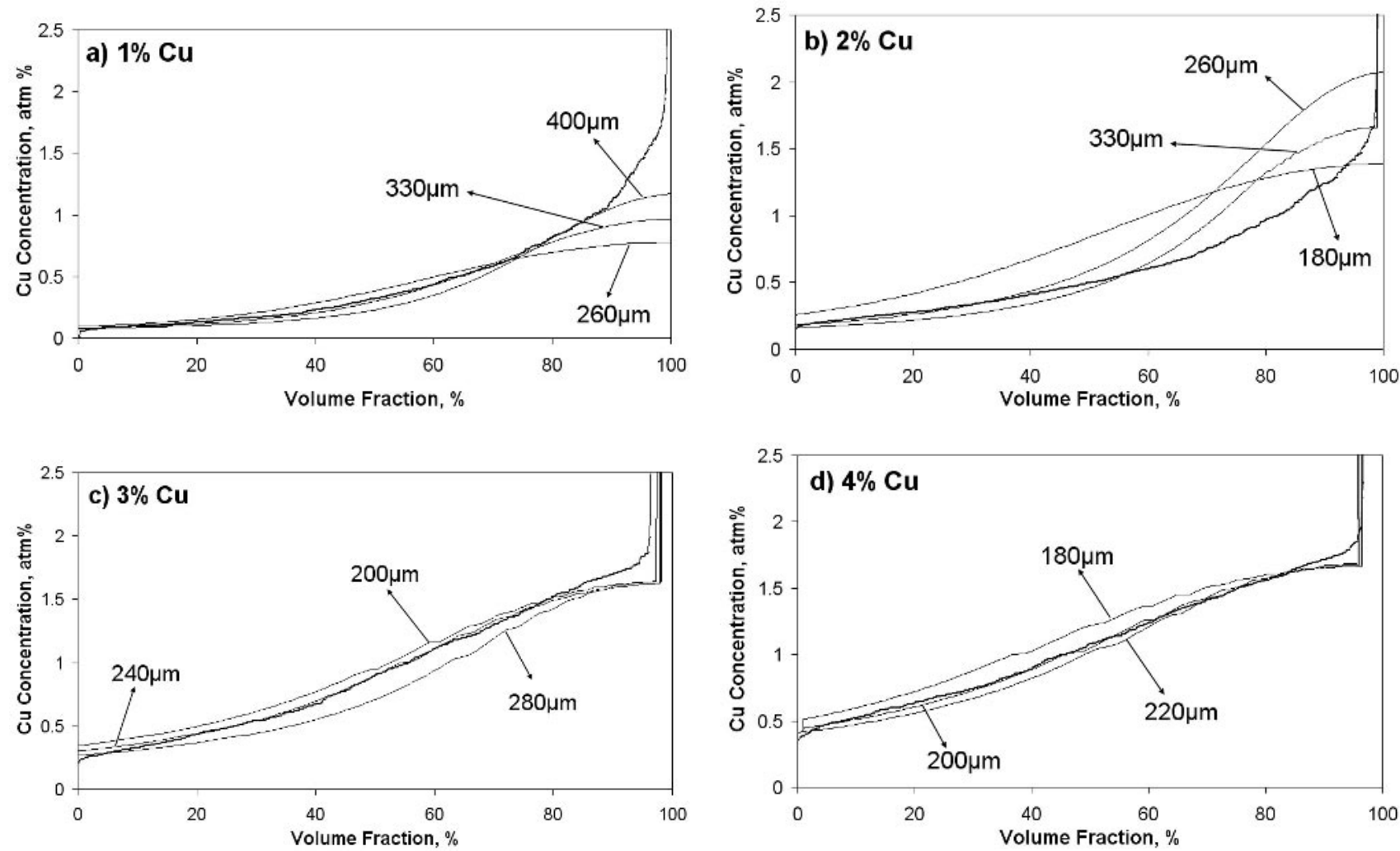

Fig. 7-Experimental ordered microsegregation plots compared with simulations: (a) 1 wt pet $\mathrm{Cu},(b) 2$ wt pet $\mathrm{Cu},(c) 3 \mathrm{wt}$ pet $\mathrm{Cu},(d) 4 \mathrm{wt}$ pct $\mathrm{Cu}$, $(e) 5$ wt pct $\mathrm{Cu},(f) 6$ wt pct $\mathrm{Cu},(g) 7$ wt pct $\mathrm{Cu}$, and $(h) 8$ wt pct $\mathrm{Cu}$. 

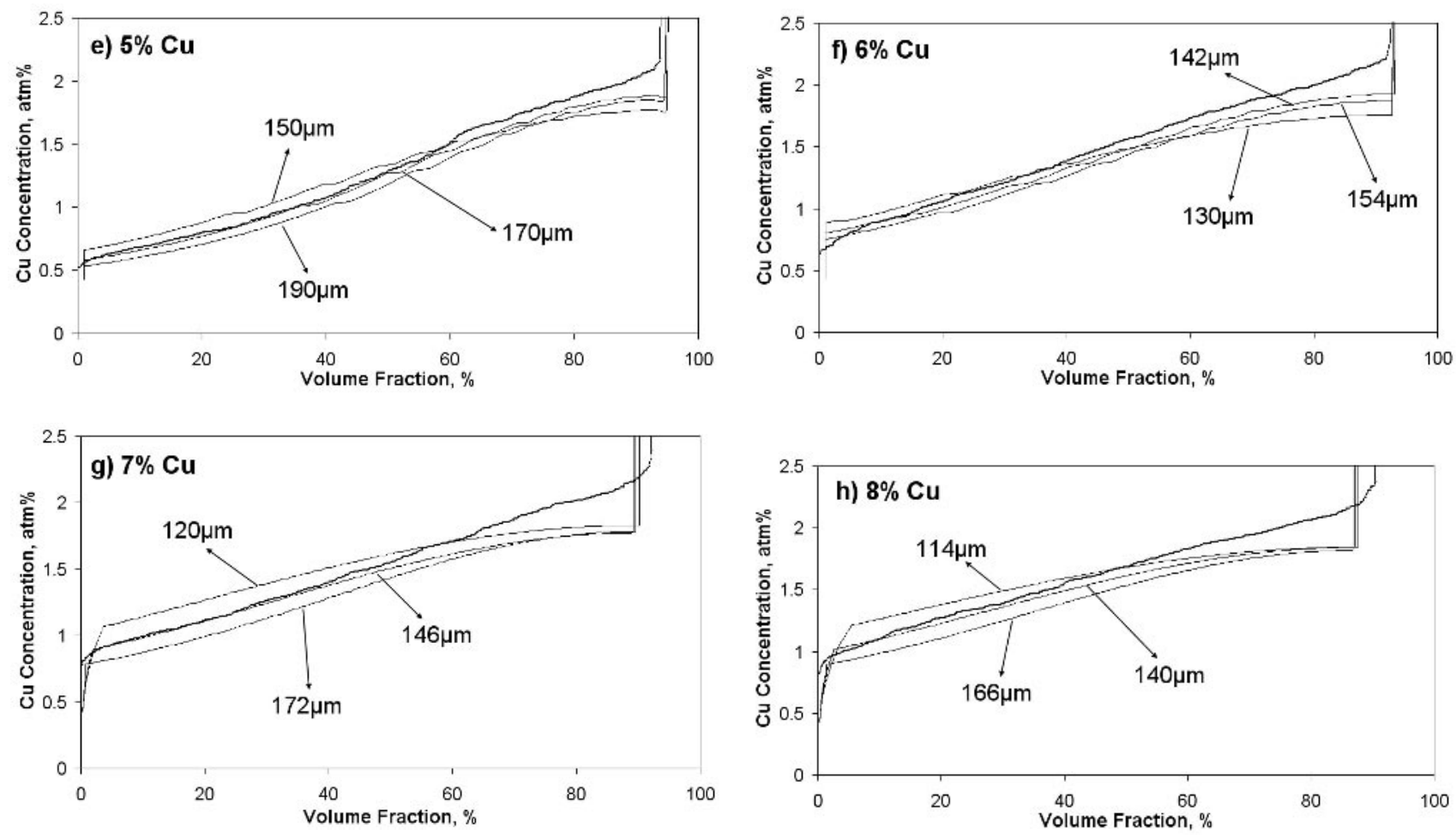

Fig. 7-(Continued). Experimental ordered microsegregation plots compared with simulations: (a) 1 wt pct $\mathrm{Cu},(b) 2$ wt pct $\mathrm{Cu},(c) 3 \mathrm{wt}$ pct $\mathrm{Cu},(d) 4$ wt pct $\mathrm{Cu},(e) 5$ wt pet $\mathrm{Cu},(f) 6$ wt pet $\mathrm{Cu},(g) 7$ wt pet $\mathrm{Cu}$, and $(h) 8$ wt pet $\mathrm{Cu}$.

highest compositions in the 5 to 8 pct $\mathrm{Cu}$ alloys, the composition varies very little with spacing (Figure 7(h)). The small variation is a result of the peak composition on the microsegregation plot, being insensitive to changes in spacing. It would be necessary for at least one spacing to have a higher concentration than that from the experiment to get a good fit at high concentrations. This was not possible for any reasonable spacing. The range of spacings does, however, explain why a small amount of eutectic was formed in the 1 and 2 pct $\mathrm{Cu}$ alloys. The eutectic forms in small pockets of liquid in the regions of largest spacing in the sample.

(3) For simplicity, the effect of coarsening ${ }^{[20,21]}$ was neglected in the present numerical model. The previous approaches ${ }^{[22-25]}$ were felt to be very approximate and introduced parameters which were not easily measured. A small increase in the solid-state diffusion coefficient could be employed to allow for coarsening. It is clear that any coarsening model would reduce the maximum height on the Gungor plot, so this omission was not felt to be the cause of the discrepancies.

(4) In the model, it is assumed that the boundary between phases is maintained at the local-equilibrium composition for the two phases. This assumption is thought to be valid for solidification of a nonfaceted material, but is less likely to be true for a solid-state reaction. From the calculations, it became apparent that the poor fit at high concentrations on the 5 to 8 pct $\mathrm{Cu}$ alloys could be because the composition on the primary $\mathrm{Al}$ side of the boundary did not follow the solvus. This could arise because the kinetics of the growth of $\mathrm{Al}_{2} \mathrm{Cu}$ was difficult, and the process should be considered to be only partially diffusion-

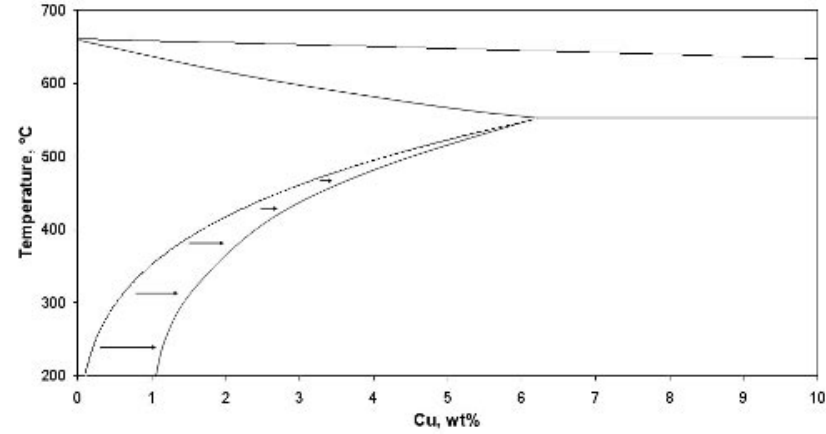

Fig. 8-Al-Cu phase diagram showing the shifted solvus.

controlled. In principal, it might be possible, knowing the growth rate of the $\mathrm{Al}_{2} \mathrm{Cu}$, to calculate how much the composition should shift, but this was not done in the present work. Instead, the position of the solvus was arbitrarily shifted (refer to the shifted solvus line in Figure 8) to determine whether departure from the equilibrium solvus would account for the present experimental results.

Figure 9 shows new simulations with the shifted solvus along with the equilibrium solvus. No change occurs for the 1 and 2 pct $\mathrm{Cu}$ samples (Figures 9(a) and (b)) due to the fact that no eutectic is formed for these compositions in the model, so the solvus is not used. However, for all the other samples, the simulation plot is shifted up, improving the fit. The shift is largest for the high-concentration alloys, giving a better overall fit with change in composition (Figures 9(e) through (h)). This fit is discussed in more detail in the following section. 

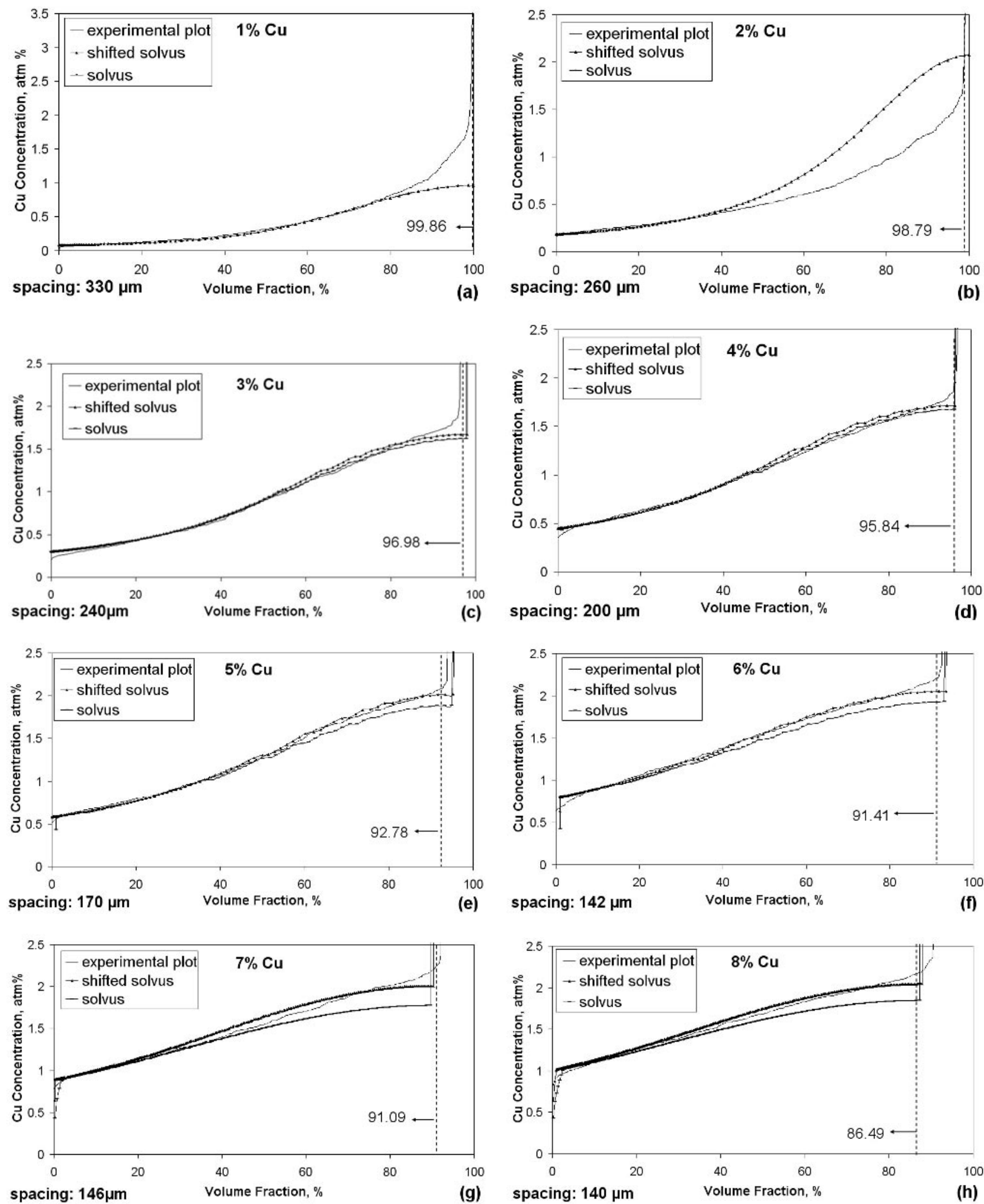

Fig. 9-Experimental ordered microsegregation plots compared with simulations using the solvus and the shifted solvus, for $(a) 1$ wt pct, $(b) 2$ wt pct, (c) $3 \mathrm{wt}$ pct, $(d) 4 \mathrm{wt}$ pct, $(e) 5 \mathrm{wt}$ pct, $(f) 6 \mathrm{wt}$ pct, $(g) 7 \mathrm{wt}$ pct, and $(h) 8 \mathrm{wt}$ pct.

\section{THE EFFECT OF SHIFTING THE SOLVUS}

The 1 pct $\mathrm{Cu}$ alloy could be fitted reasonably well by the equilibrium phase diagram for most of the sample. It is sug- gested that the poor fit at the highest volume fraction was the result of spreading near the phase boundary. The small amount of eutectic was the result of the wide range of spacings present on the sample. The eutectic forms in the regions with the 
largest spacing. The estimated spacing was $390 \mu \mathrm{m}$ (Table V), and the spacing used in the calculation was $330 \mu \mathrm{m}$.

There is a poor fit for the 2 pct $\mathrm{Cu}$ alloy both in Figures 7(b) and 9(b). It is suggested that the reason for this is that the 2 pct $\mathrm{Cu}$ alloy is near the borderline between forming eutectic and not forming eutectic at the relevant spacing. This means that very different behaviors occur over the range of spacings present on the sample. In contrast, there is a reasonable fit for the 1 pct $\mathrm{Cu}$ alloy because there is so little eutectic, and there is a reasonable fit in the 3 pct $\mathrm{Cu}$ alloy because eutectic is formed for all spacings near the average spacing.

There is a good fit for most of the volume fraction for the 3 and 4 pct $\mathrm{Cu}$ alloys (Figures 9(c) and (d)). The shifting of the solvus has little effect for these alloys. As for the 1 pct $\mathrm{Cu}$ alloy, it is suggested that spreading near the phase boundary produces the poor fit at the highest concentrations. The amount of eutectic is close to the calculated value. The estimated spacings (Table V) were 250 and $200 \mu \mathrm{m}$, and these should be compared with the spacings of 240 and $200 \mu \mathrm{m}$ used in the calculations.

There is a good fit for most of the volume fraction for the 5 and 6 pct $\mathrm{Cu}$ alloys (Figures 9(e) and (f)) for the shifted solvus. As before, it is suggested that spreading near the phase boundary produces the poor fit at the highest concentrations. The amount of eutectic is not very close to the calculated value. The estimated spacings (Table V) were 185 and $175 \mu \mathrm{m}$, and these should be compared with the spacings of 170 and $142 \mu \mathrm{m}$ used in the calculations.

There is a good fit for most of the volume fraction for the 7 and 8 pct $\mathrm{Cu}$ alloys (Figures $9(\mathrm{~g})$ and $(\mathrm{h})$ ) for the shifted solvus. As before, it is suggested that spreading near the phase boundary produces the poor fit at the highest concentrations. The amount of eutectic is close to the calculated value. The estimated spacings (Table V) were 150 and $130 \mu \mathrm{m}$, and these should be compared with the spacings of 146 and $140 \mu \mathrm{m}$ used in the calculations.

Since it is difficult to decide where the eutectic starts in the experimental composition vs volume-fraction plots, the area above the point where the composition began to rise rapidly was calculated in an attempt to make a comparison with theory. This area was then used to calculate the fraction eutectic if it were all of the eutectic composition. This procedure gives the dotted lines plotted in Figures 9(a) through (h). The fit is reasonable for most of the samples, particularly for the 7 and 8 pct $\mathrm{Cu}$ samples.

\section{SUMMARY}

The microsegregation model used in the present work has the advantage of treating diffusion below the eutectic temperature. Both the model and experiment showed that a depleted layer occurred in the $\mathrm{Al}$ near the eutectic, resulting from solid-state diffusion. It was shown that the depleted layer has a significant affect on the shape of the Gungor plot. This means that the Gungor plot is not a true microsegregation plot.

Calculations showed that a detailed fit between theory and experiment depended on the position of the solvus and the temperature dependence of the solid-state diffusion coefficient. These parameters were remeasured as an independent check. The results, although different, were not significantly different from previous work.

When the measured parameters were used in the model, the fit obtained was reasonably good. The remaining discrepancies were discussed, and the following conclusions were made.

(1) The presence of a small amount of eutectic in the 1 pct $\mathrm{Cu}$ alloy was felt to be the result of a range of spacings present on the sample; this also led to problems with the 2 pct $\mathrm{Cu}$ alloy.

(2) It was felt that the activated volume in EPMA led to some smearing at the highest $\mathrm{Cu}$ concentrations, but this could not explain the more extensive poor fit in the high$\mathrm{Cu}$-composition alloys.

(3) Modeling with a shifted solvus showed that a better fit was obtained for the high-composition alloys. It is suggested that this observation provides some evidence that local equilibrium at the interface is not achieved for the solid-state reactions below the eutectic temperature.

\section{ACKNOWLEDGMENTS}

The authors thank Alcan International Limited for financial support and supplying the samples.

\section{REFERENCES}

1. H.B. Dong, M.R.M. Shin, E.C. Kurum, H. Cama, and J.D. Hunt: Metall. Mater. Trans. A, 2003, vol. 34A, pp. 441-47.

2. H.B. Dong, M.R.M. Shin, E.C. Kurum, H. Cama, and J.D. Hunt: Fluid Phase Equilibria, 2003, vol. 212, pp. 199-208.

3. R.H. Davies, A.T. Dinsdale, T.G. Chart, T.I. Barry, and M.H. Rand: High Temp. Sci., 1990, vol. 26, pp. 251-62.

4. M.N. Gungor: Metall. Trans. A, 1989, vol. 20A, pp. 2529-33.

5. X. Yan, F. Xie, M. Chu, and Y.A. Chang: Mater. Sci. Eng., 2001, vol. A302, pp. 268-74.

6. X. Yan, S. Chen, F. Xie, and Y.A. Chang: Acta Mater., 2002, vol. 50, pp. 2199-2207.

7. D. Stockdale: J. Inst. Met., 1993, vol. 52, p. 111

8. H. Nishimura: Mem. Coll. Sci. Eng., Kyoto Imp. Univ., 1927, vol. 5, p. 61.

9. H. Liang, T. Kraft, and Y.A. Chang: Mater. Sci. Eng. A, 2000, vol. 292, pp. 96-103.

10. K. Matsuyama: Kinzoku-No-Kenkyu, 1934, vol. 11 (10), pp. 461-90.

11. M.M. Burden and J.D. Hunt: J. Cryst. Growth, 1974, vol. 22, pp. 99-109.

12. E.H. Dix and H.H. Richardson: Trans. AIME, 1926, vol. 73, p. 560.

13. H. Auer: Z. Metallkd, 1936, vol. 28, p. 164.

14. E.C. Kurum: Ph.D. Thesis, University of Oxford, Oxford, United Kingdom, 2004.

15. D. Bergner: Neue Hutte, 1984, vol. 29, pp. 207-10.

16. S. Fujikawa and K. Hirano: Mater. Sci. Forum, 1987, vols. 13-14, pp. 539-46.

17. V.R. Voller and S. Sundarraj: Mater. Sci. Technol., 1993, vol. 9, pp. 474-81.

18. J.D. Hunt and R.W. Thomas: SP97 Proc. 4th Decennial Conf. on Solidification Processing, Sheffield University, Sheffield, 1997, pp. 350-53.

19. R.W. Thomas: Ph.D. Thesis, University of Oxford, Oxford, United Kingdom, 1998, pp. 51-77.

20. W. Kurz and D.J. Fisher: Fundamentals of Solidification, 4th ed., Trans Tech Pub. Ltd., Aedermannsdorf, Switzerland, 1998, pp. 85-86.

21. M.C. Flemings: Solidification Processing, McGraw-Hill Book Company, New York, NY, 1974, pp. 148-54.

22. Z. Kattamis, J.C. Coughlin, and M.C. Flemings: Trans. AIME, 1967, vol. 239, pp. 1504-11.

23. A.J.W. Ogilvy and D.H. Kirkwood: Appl. Sci. Res., 1987, vol. 44, p. 43. 24. A.A. Howe: Appl. Sci. Res., 1987, vol. 44, p. 51.

25. A. Roósz and H.E. Exner: Acta Metall. Mater., 1990, vol. 38, pp. 375-80. 